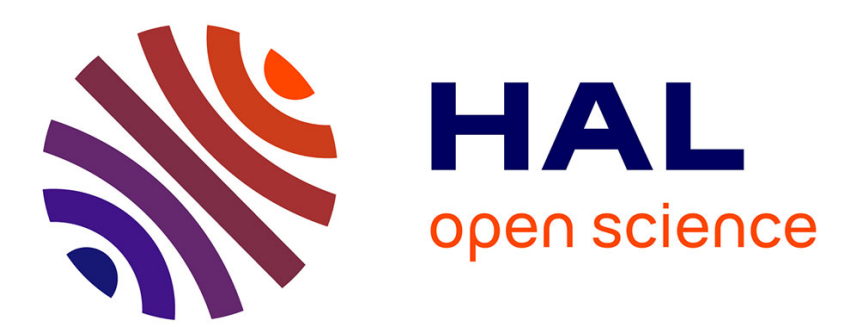

\title{
Modeling the Elongation of Nanowires Grown by Chemical Bath Deposition Using a Predictive Approach
}

Clément Lausecker, Bassem Salem, Xavier Baillin, Vincent Consonni

\section{To cite this version:}

Clément Lausecker, Bassem Salem, Xavier Baillin, Vincent Consonni. Modeling the Elongation of Nanowires Grown by Chemical Bath Deposition Using a Predictive Approach. Journal of Physical Chemistry C, 2019, 123 (48), pp.29476-29483. 10.1021/acs.jpcc.9b08958 . hal-02623990

\section{HAL Id: hal-02623990 https://hal.univ-grenoble-alpes.fr/hal-02623990}

Submitted on 26 Nov 2020

HAL is a multi-disciplinary open access archive for the deposit and dissemination of scientific research documents, whether they are published or not. The documents may come from teaching and research institutions in France or abroad, or from public or private research centers.
L'archive ouverte pluridisciplinaire HAL, est destinée au dépôt et à la diffusion de documents scientifiques de niveau recherche, publiés ou non, émanant des établissements d'enseignement et de recherche français ou étrangers, des laboratoires publics ou privés. 


\title{
Modeling the Elongation of Nanowires grown by
}

\section{Chemical Bath Deposition Using a Predictive Approach}

\author{
Clément Lausecker, ${ }^{1,2,3}$ Bassem Salem, ${ }^{*, 2}$ Xavier Baillin, ${ }^{3}$ and Vincent Consonni ${ }^{*}, 1$ \\ ${ }^{1}$ Univ. Grenoble Alpes, CNRS, Grenoble INP, LMGP, 38000 Grenoble, France \\ ${ }^{2}$ Univ. Grenoble Alpes, CNRS, LTM, F-38054 Grenoble Cedex, France \\ ${ }^{3}$ Univ. Grenoble Alpes, CEA, LETI, F-38000 Grenoble, France
}

\begin{abstract}
The chemical bath deposition of nanowires is of high interest for a wide variety of optoelectronic, piezoelectric, and sensing devices, but a theoretical description of the elongation process is still missing despite its critical importance. By solving Fick's diffusion equations in combination with thermodynamic computations, we determine the expression of the axial growth rate of nanowires and its temporal dependence under dynamic conditions, namely in a sealed reactor where the depletion of chemical reactants occurs. The theoretical model is found to be in very good agreement with a large set of experimental data specifically collected in the case of the chemical bath deposition of $\mathrm{ZnO}$ nanowires. In particular, an activation energy of $198 \pm 24 \mathrm{~kJ} / \mathrm{mol}$ is deduced for the elongation process of $\mathrm{ZnO}$ nanowires, involving the energy barriers for both the dehydration process of $\mathrm{Zn}$ (II) species (i.e. $\left[\mathrm{Zn}\left(\mathrm{H}_{2} \mathrm{O}\right)_{6}\right]^{2+}$ ions $)$ and their subsequent direct incorporation onto the $c$-plane top faces. This shows its high potential for deeply investigating the physicochemical processes at work in the chemical bath. By using the theoretical model as a predictive approach, a complete growth diagram reporting the evolution of the length of $\mathrm{ZnO}$ nanowires vs effective growth time and temperature is also gained over a broad range of conditions, revealing its additional high potential for applied research and industrial purposes. The present general approach is further compatible with a broad range of chemicals in solution and of semiconducting materials grown by chemical bath deposition.
\end{abstract}




\section{INTRODUCTION}

As a low-cost, low-temperature, and easily implemented process, chemical bath deposition (CBD) is of great interest to form nanostructures with a dedicated structural morphology. ${ }^{1,2}$ It is further compatible with a variety of applications in the fields of optoelectronics, ${ }^{3-5}$ piezoelctricity,,${ }^{6,7}$ and sensing, ${ }^{8}$ and it can be scaled up for industrial purposes. ${ }^{9}$ One of the most-well known use of CBD over the last decade has been devoted to the formation of $\mathrm{ZnO}$ nanostructures, mainly nanowires (NWs), using the spontaneous and selective area growths on a variety of flexible

and rigid substrates. ${ }^{10-14}$ A reactor containing the bath comprising the chemical precursors composed of a zinc salt and an ammine mixed in aqueous solution is typically sealed and placed in an oven heated at a temperature in the range of $60-90{ }^{\circ} \mathrm{C} .{ }^{15-18}$ The CBD process induces the heterogeneous formation of $\mathrm{ZnO}$ NWs that is achieved on a dedicated nucleation surface, e.g. a $\mathrm{ZnO}$ polycrystalline seed layer ${ }^{19-21}$ or single crystal, ${ }^{22,23}$ or a metallic seed layer. $^{24-26}$ In the most widely used case of a sealed reactor, ${ }^{11,16,18,25,26}$ the system is thus closed with no continuous addition of chemical precursors during the CBD process, which corresponds to dynamic conditions. The axial growth rate of $\mathrm{ZnO}$ NWs is thus basically not constant over time and decreases as their elongation proceeds owing to the depletion of the chemical bath in reactants, typically the $\mathrm{Zn}(\mathrm{II})$ ions as the limiting species. As a result, the elongation of $\mathrm{ZnO} \mathrm{NWs}$ and specifically its temporal dependence has emerged as a critical issue both for fundamental research purposes aiming at more deeply understanding the physicochemical processes at work as well as for applied research and industrial purposes targeting the massive production of $\mathrm{ZnO}$ NWs.

However, despite its primary importance, the theoretical modeling of the elongation process of $\mathrm{ZnO}$ NWs by CBD through the expression of its axial growth rate has so far been limited to static conditions, ${ }^{27-29}$ namely in a continuous flow reactor. No temporal dependence has been reported to take into account dynamic conditions in a sealed reactor originating from the depletion of the chemical bath in reactants. Boercker et al. showed that the length of $\mathrm{ZnO}$ NWs is inversely proportional to its surface density in a growth regime limited by the diffusive transport of chemical reactants. ${ }^{27}$ Later on, Cheng et al. established a comprehensive analysis of the surface reaction-/diffusive transport-limited growth regimes to get the expression of the axial growth rate under homeostatic conditions. ${ }^{28}$ They developed a continuous flow reactor maintaining homeostatic chemical precursor concentrations and constant growth temperature to successfully investigate the elongation process of $\mathrm{ZnO}$ NWs. Cossuet et al. 
subsequently reported that $\mathrm{Zn}$-polar $\mathrm{ZnO}$ nanorods have a higher growth rate than $\mathrm{O}$-polar $\mathrm{ZnO}$ nanorods owing to their larger surface reaction rate constant by using the same analysis as in Ref. ${ }^{28} .{ }^{29}$ In the present case, the reactor was sealed and thus the system was closed, but the active surface area for the selective area growth of $\mathrm{ZnO}$ nanorods on patterned $\mathrm{ZnO}$ single crystals was very small as compared to the sample size and solution volume, somehow corresponding to static conditions.

In this article, we establish and develop a theoretical model of the axial growth rate of ZnO NWs by CBD and of its temporal dependence under dynamic conditions in the framework of the surface reaction-/diffusive transportlimited growth regime analysis in combination with thermodynamic computations. The theoretical modeling is applied to the elongation process of $\mathrm{ZnO} \mathrm{NWs}$ when grown in a broad range of CBD conditions in order to reveal the physicochemical processes at work on their $c$-plane top faces. These findings further reporting a predictive approach of the CBD process under dynamic conditions are of high and broad interest for a wide variety of chemicals in solution and of semiconducting materials in the framework of NW growth.

\section{EXPERIMENTAL SECTION}

2.1. Seed layer deposition. The $2 \times 2 \mathrm{~cm}^{2}$ samples were prepared from $\mathrm{Si}$ (100) substrates cleaned with acetone and isopropyl alcohol in an ultrasonic bath. In order to perform the $\mathrm{ZnO}$ seed layer deposition, a solution containing $375 \mathrm{mM}$ of zinc acetate dihydrate $\left(\mathrm{Zn}\left(\mathrm{CH}_{3} \mathrm{COO}\right)_{2} \cdot 2 \mathrm{H}_{2} \mathrm{O}\right.$, Sigma-Aldrich) and $375 \mathrm{mM}$ of monoethanolamine (MEA, Sigma-Aldrich) in pure ethanol was prepared and stirred for several hours at $60{ }^{\circ} \mathrm{C}$ on a hot plate and then at room temperature. The substrates were subsequently dipped in the solution under a controlled atmosphere (<15\% hygrometry) and annealed for $10 \mathrm{~min}$ at $300{ }^{\circ} \mathrm{C}$ to evaporate residual organic compounds and for $1 \mathrm{~h}$ at $500{ }^{\circ} \mathrm{C}$ to crystallize the $\mathrm{ZnO}$ seed layer.

2.2. Synthesis of $\mathbf{Z n O}$ NWs. ZnO NWs were then grown by CBD with a chemical bath containing an aqueous solution of zinc nitrate hexahydrate $\left(\mathrm{Zn}\left(\mathrm{NO}_{3}\right)_{2} \cdot 6 \mathrm{H}_{2} \mathrm{O}\right.$, Sigma-Aldrich) and hexamethylenetetramine (HMTA, Sigma-Aldrich) mixed in an equimolar ratio of $30 \mathrm{mM}(\mathrm{pH}=6.9)$. To increase the $\mathrm{pH}$ to $11.0,800 \mathrm{mM}$ of ammonia $\left(\mathrm{NH}_{3}\right.$, Sigma-Aldrich) was further added to the chemical bath. The samples were placed face down in a sealed reactor containing the precursor solution and heated in a regular oven at $80-95{ }^{\circ} \mathrm{C}$ in the range of $40 \mathrm{~min}$ to $8 \mathrm{~h}$. 
2.3. Morphological characterization. The morphological properties of $\mathrm{ZnO}$ NWs were investigated with a FEI Quanta 250 field-emission scanning electron microscope (FESEM). By using ImageJ software, the $c$ plane surface area ratios of $\mathrm{ZnO}$ NWs were assessed from top-view FESEM images, in which a filter was applied to only display their $c$-plane top facets. Moreover, the mean lengths of $\mathrm{ZnO} \mathrm{NWs}$ were measured from crosssectional view FESEM images. The numerical values are summarized in Table S1.

2.4. Thermodynamic simulations. Thermodynamic simulations were performed using Visual MINTEQ software for determining the equilibrium concentration of $\mathrm{Zn}$ (II) ions as a function of the growth temperature and $\mathrm{NH}_{3}$ concentration. ${ }^{15,49} \mathrm{Zn}^{2+}$ ion was considered as a single metallic cation, which is able to form complexes with two possible ligands, namely $\mathrm{NH}_{3}$ and $\mathrm{HO}^{-}$, denoted as L, by following the general reaction: $n \mathrm{Zn}^{2+}$ $+i \mathrm{~L} \leftrightarrow \mathrm{Zn}_{n} \mathrm{~L}_{i}^{2 \mathrm{n}+}$ where $\mathrm{Zn}_{n} \mathrm{~L}_{i}^{2 \mathrm{n}+}$ is the complex considered and $i$ the coordination number. The global thermodynamic equilibrium is calculated from the stability constants $\beta_{i}^{L}=\frac{\left[Z n_{n} L_{i}^{2 n+}\right]}{\left[Z n^{2+}\right]^{n}[L]^{i}}$ associated with each chemical reaction, whose the typical values were taken from NIST database.

\section{RESULTS AND DISCUSSION}

\subsection{Description of the theoretical model under dynamic conditions. We consider a semi-}

infinite reactor - as defined for $z>0$ - where an infinite substrate is placed at $z=0$ as seen in Figure 1. In order to estalish the expression of the length of $\mathrm{ZnO}$ NWs and its temporal dependence, namely their elongation under dynamic conditions where the depletion of chemical reactants occurs, we apply Fick's second diffusion equation in one dimension as follows: ${ }^{30}$

$$
\frac{\partial C}{\partial t}=D \frac{\partial^{2} C}{\partial z^{2}}
$$

with the three following boundary conditions:

$$
\begin{gathered}
C(z, t=0)=C_{0} \\
C(z=\infty, t)=C_{0} \\
\frac{d C(z=0, t)}{d z}=\frac{k_{1} S}{D}\left(C(z=0, t)-C_{e q}\right)
\end{gathered}
$$

where $C(z, t)$ is the concentration of $\mathrm{Zn}(\mathrm{II})$ ions $\left(\mathrm{m}^{-3}\right)$ at a height $z$ above the substrate and at arowth time $t, C_{e q}$ is the equilibrium concentration of $\mathrm{Zn}$ (II) ions $\left(\mathrm{m}^{-3}\right), k_{1}$ is the first order reaction rate constant of $\mathrm{ZnO}$ crystallization 
$\left(\mathrm{m} . \mathrm{s}^{-1}\right), S$ is the $c$-plane top surface area ratio and $D$ is the diffusion coefficient of $\mathrm{Zn}(\mathrm{II})$ ions in aqueous solution at the temperature $T\left(\mathrm{~m}^{2} \cdot \mathrm{s}^{-1}\right)$.

Eqs. 2 and 3 report that $C_{0}$ corresponds to the concentration of $\mathrm{Zn}(\mathrm{II})$ ions at $t=0$ wherever in the chemical bath and is assumed to match the concentration of $\mathrm{Zn}(\mathrm{II})$ ions located infinitely far from the substrate at any $t$. Eq.4 accounts for the consumption of the limiting reactants (i.e. $\mathrm{Zn}$ (II) ions) on the growth front located at the $c$-plane top facet of ZnO NWs. It is obtained by applying Fick's first diffusion equation at $z=0$ by further neglecting the development of the growth front with time as well as by considering $S$ as a constant parameter in a first appoximation.

In order to solve this second-order partial differential equation, we apply the Laplace transform to Eq.1, and, by using Eq.2, we obtain:

$$
\frac{\partial^{2} c}{\partial z^{2}}-\frac{p}{D} c=\frac{-C_{0}}{D}
$$

where $c(z, p)$ is the Laplace transform of $C(z, t)$. The temporal derivative is thus removed and we get an ordinary differential equation. By solving Eq.5 with Eqs.3 and 4, we obtain:

$$
c(z, p)=\frac{C_{0}}{p}-\frac{\frac{k_{1} S}{D}\left(C_{0}-C_{e q}\right)}{p\left(\sqrt{\frac{p}{D}}+\frac{k_{1} S}{D}\right)} \exp \left(-\sqrt{\frac{p}{D}} z\right)
$$

By applying the inverse Laplace transform to Eq.6, we get the following expression:

$$
C(z, t)=\left(C_{0}-C_{e q}\right)\left[\operatorname{erf}\left(\frac{z}{2 \sqrt{D t}}\right)+\exp \left(\frac{k_{1} S}{D} z+\frac{\left(k_{1} S\right)^{2}}{D} t\right) \operatorname{erfc}\left(\frac{z}{2 \sqrt{D t}}+\frac{k_{1} S}{\sqrt{D}} \sqrt{t}\right)\right]+C_{e q}
$$

In order to deduce the time-dependent axial growth rate of $\mathrm{ZnO} N W s$ denoted as $R_{c}(t)$, we consider the relation:

$$
R_{c}(t)=\frac{k_{1}}{\rho}\left(C(z=0, t)-C_{e q}\right)
$$

where $\rho$ is the atomic density of wurtzite $\mathrm{ZnO}$ that is equal to $4.20 \times 10^{28} \mathrm{~m}^{-3}$. This directly gives:

$$
R_{c}(t)=\frac{\left(C_{0}-C_{e q}\right) k_{1}}{\rho}\left[\exp \left(\frac{\left(k_{1} S\right)^{2}}{D} t\right) \operatorname{erfc}\left(\frac{k_{1} S}{\sqrt{D}} \sqrt{t}\right)\right]
$$

The length of $\mathrm{ZnO}$ NWs denoted as $L$ and its temporal dependence is, in turn, deduced by integrating Eq.9, which yields: 


$$
L(t)=\frac{\left(C_{0}-C_{e q}\right) D}{\rho k_{1} S^{2}}\left[\exp \left(\frac{\left(k_{1} S\right)^{2}}{D} t\right) \operatorname{erfc}\left(\frac{k_{1} S}{\sqrt{D}} \sqrt{t}\right)+2 k_{1} S \sqrt{\frac{t}{D \pi}}-1\right]
$$

In the following, we define $\Delta C$ as $C_{0}-C_{e q}$, which represents the effective concentration involved in the elongation process of ZnO NWs. A more detailed proof to get Eq.10 is available in Supporting Information.

As a direct comparison, we also consider the axial growth rate of $\mathrm{ZnO} \mathrm{NW}$ under static conditions denoted as $R_{C}^{\text {static }}$ as given in Refs. ${ }^{27-29}$ by:

$$
L(t)=R_{c}^{\text {static }} t=\frac{k_{1} C_{0} D}{\rho D+\rho \delta k_{1} S} t
$$

where $\delta$ is the stagnant layer thickness (m), i.e. the thickness of fluid above the $\mathrm{ZnO}$ NWs subjected to the diffusive transport of $\mathrm{Zn}(\mathrm{II})$ ions.

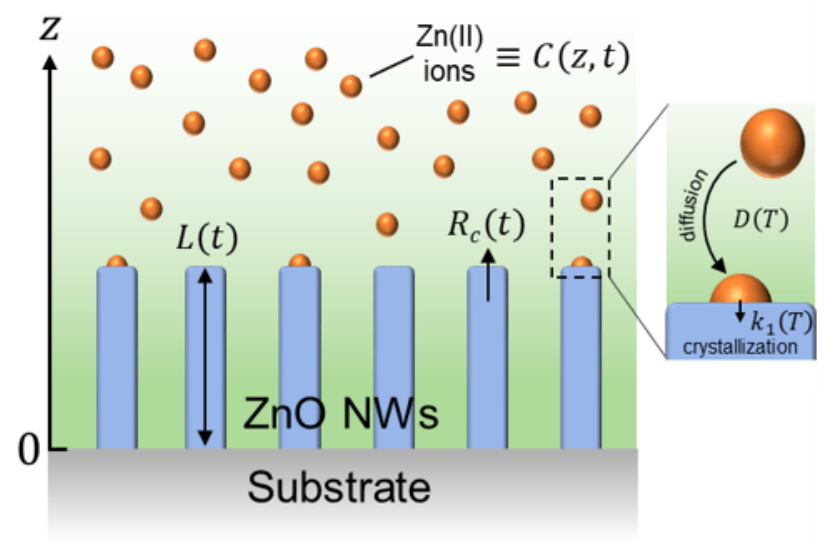

Figure 1. Schematic of the geometry used to establish the theoretical model of the axial growth rate of ZnO NWs by $\mathrm{CBD}$ and its temporal dependence under dynamic conditions (i.e. considering the depletion of chemical reactants).

Under dynamic conditions where the depletion of chemical reactants is considered (i.e., using a sealed reactor), we deduce from Eq.9 that the axial growth rate of $\mathrm{ZnO}$ NWs decreases by increasing the growth time, which implies, from Eq.10, that their elongation nonlinearly increases. In contrast, under static conditions where no depletion of chemical reactants is taken into account (i.e., using a continuous flow reactor), the axial growth rate of $\mathrm{ZnO}$ NWs is constant and Eq.11 clearly reveals that their elongation linearly increases. This nonlinearity has thus not been considered in the previous theoretical model under static conditions as reported in Refs. ${ }^{27-29}$, although it has been revealed by typical experimental data reporting the evolution of the length of $\mathrm{ZnO}$ NWs with growth time under dynamic conditions. ${ }^{31-33}$ 
Additionally, the equilibrium concentration of $\mathrm{Zn}(\mathrm{II})$ ions denoted as $C_{e q}$, for which its value depends on the CBD conditions, was assessed for a given set of growth parameters through dedicated thermodynamic calculations by using Visual MINTEQ software. The evolution of $C_{e q}$ as a function of the $\mathrm{NH}_{3}$ concentration (i.e. of the $\mathrm{pH}$ ) at different temperatures is presented in Figure 2 for a chemical bath containing an equimolar concentration $C_{0}$ of $\mathrm{Zn}\left(\mathrm{NO}_{3}\right)_{2}$ and HMTA of $30 \mathrm{mM}$. We see that $C_{e q}$ is strongly dependent upon the $\mathrm{NH}_{3}$ concentration, and hence cannot be neglected in most cases. In particular, for a $\mathrm{NH}_{3}$ concentration of $30 \mathrm{mM}$ corresponding in a first approximation to what is typically provided by the hydrolysis of HMTA, $C_{e q}$ is as high as $15.2 \mathrm{mM}$, dividing by more than a half the available concentration of $\mathrm{Zn}$ (II) species for the elongation of $\mathrm{ZnO} \mathrm{NWs}$. Two growth regimes can further be identified: i) below a $\mathrm{NH}_{3}$ concentration of $60 \mathrm{mM}, C_{e q}$ does not depend on the growth temperature and the remaining $\mathrm{Zn}(\mathrm{II})$ species are mainly in the form of $\mathrm{Zn}^{2+}$ ions, ii) above a $\mathrm{NH}_{3}$ concentration of $250 \mathrm{mM}$, $C_{e q}$ depends on the growth temperature and the remaining $\mathrm{Zn}(\mathrm{II})$ species are mostly in the form of $\mathrm{Zn}\left(\mathrm{NH}_{3}\right)_{4}{ }^{2+}$ ions. When the $\mathrm{NH}_{3}$ concentration lies in the range of $60-250 \mathrm{mM}, C_{e q}$ is negligible, reflecting very high supersaturation levels. However, these CBD conditions are known to be experimentally unfavorable for the heterogeneous formation of $\mathrm{ZnO}$ NWs onto the substrate, because a large amount of $\mathrm{ZnO}$ is homogeneously formed in the bulk solution due to very high supersaturation levels. ${ }^{34}$ Additionally, although the evolution of $C_{e q}$ in Figure 2 was plotted for a given $C_{0}$ of $30 \mathrm{mM}$, it should be noted here that $C_{e q} \sim 0.5 C_{0}$ in the $C_{0}$ typical range of $10-100 \mathrm{mM}$ when no $\mathrm{NH}_{3}$ is added. In other words, the proportion of remaining $\mathrm{Zn}$ (II) species is unchanged when the equimolar concentration of $\mathrm{Zn}\left(\mathrm{NO}_{3}\right)_{2}$ and HMTA is varied from 10 to $100 \mathrm{mM}$ and when no $\mathrm{NH}_{3}$ is added. The influence of the homogeneous growth is basically not described by the present model.

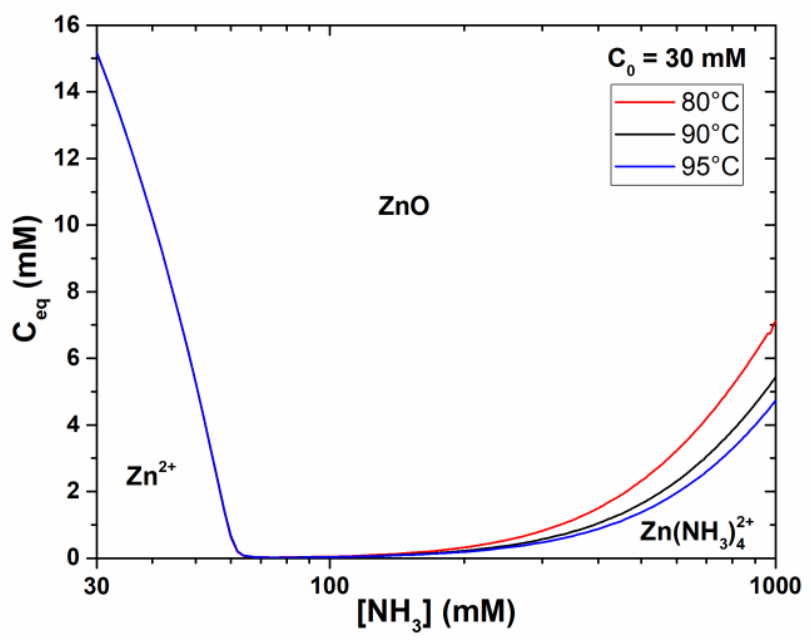


Figure 2. Concentrations of dissolved and crystallized $\mathrm{Zn}$ (II) ions when thermodynamic equilibrium is reached, as computed with Visual MINTEQ for $C_{0}=30 \mathrm{mM}$ and $\mathrm{T}=80,90$ and $95^{\circ} \mathrm{C}$. The plotted curve directly gives the value of $C_{e q}$.

\subsection{Investigation of the fundamental physicochemical processes during CBD by using}

the theoretical model. In order to assess the consistency and reliability of our theoretical model with respect to experimental data, we first consider CBD conditions where the homogeneous growth can be neglected. In that purpose, a first series of samples of $\mathrm{ZnO} N W s$ was grown at $90{ }^{\circ} \mathrm{C}$ in a chemical bath containing $30 \mathrm{mM}$ of $\mathrm{Zn}\left(\mathrm{NO}_{3}\right)_{2}$ and HMTA as well as $800 \mathrm{mM}$ of $\mathrm{NH}_{3}$ mixed in aqueous solution, giving rise to an initial $\mathrm{pH}$ of 11.0. The total growth time was further varied in the range from $40 \mathrm{~min}$ to $8 \mathrm{~h}$. As expected, the length of ZnO NWs continuously increases with growth time, as shown in Figure 3. Interestingly, no significant homogeneous growth occurs in the chemical bath under these CBD conditions, even for the growth time of $8 \mathrm{~h}$, as revealed in Figure S1a-c. This clearly indicates that the homogeneous growth is overall negligible for the present CBD conditions.

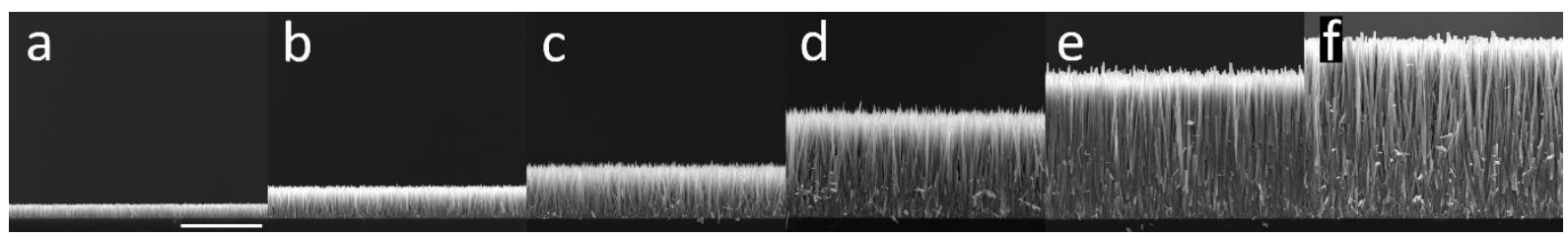

Figure 3. Cross-sectional view FESEM images of $\mathrm{ZnO}$ NWs grown by $\mathrm{CBD}$ at $90{ }^{\circ} \mathrm{C}$ with $30 \mathrm{mM}$ of $\mathrm{Zn}\left(\mathrm{NO}_{3}\right)_{2}$ and HMTA as well as $800 \mathrm{mM}$ of $\mathrm{NH}_{3}$ for (a) $40 \mathrm{~min}$, (b) $1 \mathrm{~h}$, (c) $1.5 \mathrm{~h}$, (d) $3 \mathrm{~h}$, (e) $5 \mathrm{~h}$ and, (f) $8 \mathrm{~h}$, respectively. The scale bar represents $5 \mu \mathrm{m}$.

The mean length of $\mathrm{ZnO}$ NWs as deduced from cross-sectional view FESEM images in Figure $\mathbf{3}$ is presented in Figure 4, where its evolution as a function of effective growth time is fitted by Eqs.11 and 10 using both theoretical models under static and dynamic conditions, respectively. It should be noted here that the effective growth time is actually introduced by considering the thermalization time of $35 \mathrm{~min}$ for the chemical bath to reach $90{ }^{\circ} \mathrm{C} . S$ values, as deduced from top-view FESEM images in Figure S2, are further found to be fairly constant and a mean $S$ value of 0.27 is then considered. The linear fit from Eq. 11 yields $R_{C}^{\text {static }}=1.90 \mu \mathrm{m} / \mathrm{h}$. By using $C_{0}=30$ $\mathrm{mM}$ and $\delta=3.8 \mathrm{~mm}^{29}$ along with $D=2.74 \times 10^{-9} \mathrm{~m}^{2} / \mathrm{s}^{35}$, a low value of $k_{1}$ around $2.28 \mu \mathrm{m} / \mathrm{s}$ is obtained. However, we can immediately notice that the linear fit provided by Eq.11 has a very poor agreement with the experimental data, as it fails to predict the decrease in the axial growth rate of $\mathrm{ZnO} \mathrm{NWs}$ with effective growth time. In contrast, by setting $\Delta C$ and $k_{1}$ as the only free fit parameters in Eq.10, a very good agreement with the experimental data is 
reached for $\Delta C=22.4 \mathrm{mM}$ and $k_{1}=19.4 \mu \mathrm{m} / \mathrm{s}$. It is worth noticing that thermodynamic calculations predict $\Delta C=$ $26.2 \mathrm{mM}$ under these CBD conditions as seen in Figure 2, which is in good accordance with the fitted value. The small difference can be explained by a residual homogeneous growth that still occurs in the chemical bath, lowering in turn the available precursor concentration for the elongation process of $\mathrm{ZnO} \mathrm{NWs}$ on the substrate. As a consequence, the theoretical model under static conditions should only be used to describe the axial growth rate of $\mathrm{ZnO}$ NWs in particular cases - as when a continuous flow reactor is used for instance ${ }^{28}-$ while our theoretical model under dynamic conditions can be applied to describe the axial growth rate of $\mathrm{ZnO} \mathrm{NWs}$ in the vast majority of cases - as when a sealed reactor is used.

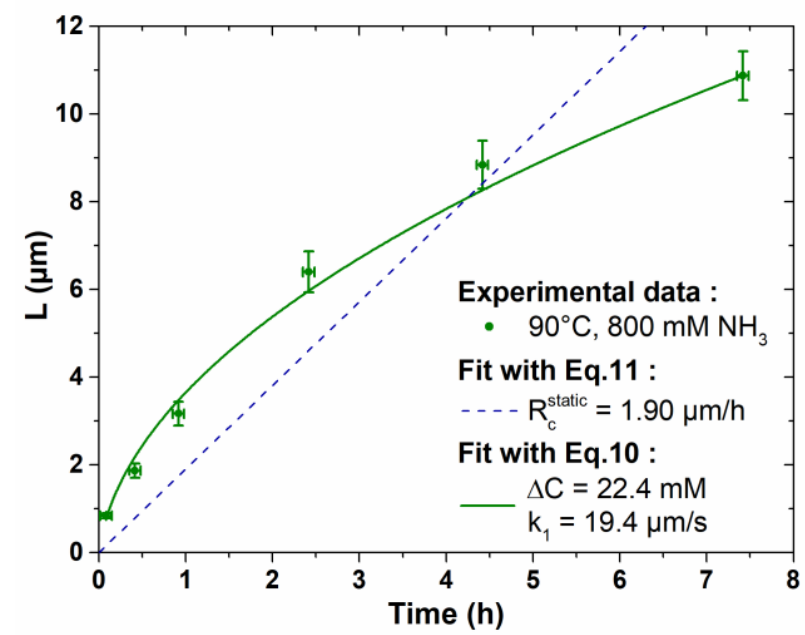

Figure 4. Length versus effective growth time of $\mathrm{ZnO} N W$ s grown by $\mathrm{CBD}$ at $90{ }^{\circ} \mathrm{C}$ with $30 \mathrm{mM}$ of $\mathrm{Zn}\left(\mathrm{NO}_{3}\right)_{2}$ and HMTA as well as $800 \mathrm{mM}$ of $\mathrm{NH}_{3}$. The experimental data were fitted by Eq.11 with $R_{c}^{\text {static }}=1.90 \mu \mathrm{m} / \mathrm{h}$ using the theoretical model under static conditions, and by Eq.10 with $\Delta C=22.4 \mathrm{mM}, k_{1}=19.4 \mu \mathrm{m} / \mathrm{s}, S=0.27$, $D=2.74 \times 10^{-9} \mathrm{~m}^{2} / \mathrm{s}$, and $\rho=4.20 \times 10^{28} \mathrm{~m}^{-3}$ using the theoretical model under dynamic conditions, respectively.

As the theoretical model under dynamic conditions has successfully described the evolution of the length of ZnO NWs with growth time when no significant homogeneous growth occurs, we can now use it in more typical, general cases to gain a deeper understanding of the fundamental physicochemical processes in the CBD. In particular, the temperature dependence of the surface reaction rate constant $k_{1}$ in Eqs.10 and 11 has not been determined yet despite its strong interest to reveal the mechanisms at work during the elongation process of $\mathrm{ZnO}$ NWs. In that purpose, three series of samples were grown respectively at 80,90 and $95{ }^{\circ} \mathrm{C}$ in a chemical bath containing $30 \mathrm{mM}$ of $\mathrm{Zn}\left(\mathrm{NO}_{3}\right)_{2}$ and HMTA mixed in aqueous solution, giving rise to an initial $\mathrm{pH}$ of 6.9. The total growth time was again varied in the range from $40 \mathrm{~min}$ to $8 \mathrm{~h}$. As $\mathrm{NH}_{3}$ is usually not used to perform $\mathrm{CBD}$, it was not added to the chemical bath here. As a result, the homogeneous growth is much more pronounced as seen in 
Figure S1d-f and it turns out to mostly occur at the very beginning of the CBD. Therefore, to take into account its influence in the theoretical model under dynamic conditions, we make the assumption that it occurs instantaneously at a growth time $t=0$. The effective concentration involved in the elongation process of $\mathrm{ZnO} \mathrm{NWs}$ denoted as $\Delta C$ is thus expected to be lower than the predicted value of $14.8 \mathrm{mM}$ for these CBD conditions. Moreover, the equilibrium concentration $C_{e q}$ - and in turn the supersaturation level - is not dependent upon the growth temperature in this range of $\mathrm{pH}$ as revealed in Figure 2. Then, we also assume that $\Delta C$ does not vary with temperature. As expected again, the length of $\mathrm{ZnO}$ NWs continuously increases with growth time regardless of the growth temperature, as shown in Figure 5a-g, S3, and S4. The mean length of ZnO NWs as deduced from these cross-sectional view FESEM images is presented in Figure 5h, where its evolutions as a function of effective growth time are fitted by Eq.10 using the theoretical model under dynamic conditions. For the same reasons as before, the effective growth time is introduced by subtracting the thermalization time of 35 min to the total growth time and a mean $S$ value of 0.27 is considered. Furthermore, we use $D=2.38 \times 10^{-9} \mathrm{~m}^{2} / \mathrm{s}$ at $80^{\circ} \mathrm{C}, D=2.74 \times 10^{-9}$ $\mathrm{m}^{2} / \mathrm{s}$ at $90{ }^{\circ} \mathrm{C}$, and $D=2.93 \times 10^{-9} \mathrm{~m}^{2} / \mathrm{s}$ at $95{ }^{\circ} \mathrm{C} .{ }^{35}$ For the fitting procedure, only the series at $90{ }^{\circ} \mathrm{C}$ with $\Delta C$ and $k_{1}$ set as the only free fit parameters is first considered, where the relation $3.31 \mathrm{~m}^{-2} \cdot \mathrm{s}^{-1}<\Delta C . k_{1} \times 10^{-19}<5.34 \mathrm{~m}^{-}$ ${ }^{2} . \mathrm{s}^{-1}$ must be fulfilled for the sake of consistency with Ref. ${ }^{29}$ (see Supporting Information). A very good agreement with the experimental data is found for $\Delta C=3.93 \mathrm{mM}$ and $k_{1}=18.2 \mu \mathrm{m} / \mathrm{s}$. The strong effect of the homogeneous growth at that $\mathrm{pH}$ is seen in the fitted value of $\Delta C$, which is much lower than its predicted value of $14.8 \mathrm{mM}$ by thermodynamic calculations as given in Figure 2. Interestingly, it should also be noted that the different growth kinetics at $90{ }^{\circ} \mathrm{C}$ with or without the addition of $\mathrm{NH}_{3}$ originate from the only variation of $\Delta C$, while $k_{1}$ keep a similar value in both cases. This suggests that the mechanisms involved during the elongation process of $\mathrm{ZnO}$ NWs at low and high $\mathrm{pH}$ are similar. Second, the series at 80 and $95{ }^{\circ} \mathrm{C}$ are subsequently fitted with $\Delta C=3.93 \mathrm{mM}$ and $k_{1}$ as the only free fit parameter. A very good agreement with the experimental data is found for $k_{1}=2.65 \mu \mathrm{m} / \mathrm{s}$ at $80{ }^{\circ} \mathrm{C}$ and $k_{1}=40.8 \mu \mathrm{m} / \mathrm{s}$ at $95^{\circ} \mathrm{C}$, respectively. From these $k_{1}$ values in the range of 80 to $95^{\circ} \mathrm{C}$, the Arrhenius plot of $k_{1}$, i.e. the graph of $\ln \left(k_{1}\right)=f\left(\frac{1}{T}\right)$, is established in Figure 5i. The excellent agreement with the experimental data indicates that the elongation process of $\mathrm{ZnO}$ NWs is thermally activated. By using the Arrhenius equation, ${ }^{36}$ we deduce an activation energy $E_{A}$ of $198 \pm 24 \mathrm{~kJ} / \mathrm{mol}$. This value is higher than the activation energy reported in Ref. ${ }^{28}$ using classical crystal growth theory. ${ }^{37}$ However, their approach only considers the activation 
energy required for the direct incorporation of $\mathrm{Zn}^{2+}$ ions - which are the dominant $\mathrm{Zn}(\mathrm{II})$ species under these CBD conditions - onto the $c$-plane faces of $\mathrm{ZnO} \mathrm{NWs}$. In contrast, as $\mathrm{Zn}^{2+}$ ions are well-known to form octahedral complexes with water molecules - i.e. $\left[\mathrm{Zn}\left(\mathrm{H}_{2} \mathrm{O}\right)_{6}\right]^{2+}-$ in aqueous solution, ${ }^{38-41}$ a dehydration step is required before their direct incorporation onto the $c$-plane faces of $\mathrm{ZnO}$ NWs. It has been further confirmed that no intermediates in the form of zinc hydroxide phases are involved in the crystallization process for the present CBD conditions. ${ }^{42}$ $A b$ initio calculations have shown that the energy of hydration of six water molecules on a $\mathrm{Zn}^{2+}$ ion lies in the range of -1600 to $-1400 \mathrm{~kJ} / \mathrm{mol}^{40,43-46}$ revealing a very high energy barrier for the complete dehydration of the ion in aqueous solution. However, this barrier is presumably much lower on the $c$-plane faces of ZnO NWs where the dehydration process may be assisted by the surface. Also, a partial dehydration of $\mathrm{Zn}^{2+}$ ions might be sufficient for its direct incorporation onto the $c$-plane faces of $\mathrm{ZnO} N W s$, leading in turn to a massive incorporation of hydrogen in their center as reported in Ref. ${ }^{47}$. Therefore, the relatively high activation energy we obtain is most likely explained by both processes of dehydration of $\left[\mathrm{Zn}\left(\mathrm{H}_{2} \mathrm{O}\right)_{6}\right]^{2+}$ ions and of incorporation of $\mathrm{Zn}(\mathrm{II})$ species at the $c$ plane top faces of $\mathrm{ZnO}$ NWs.
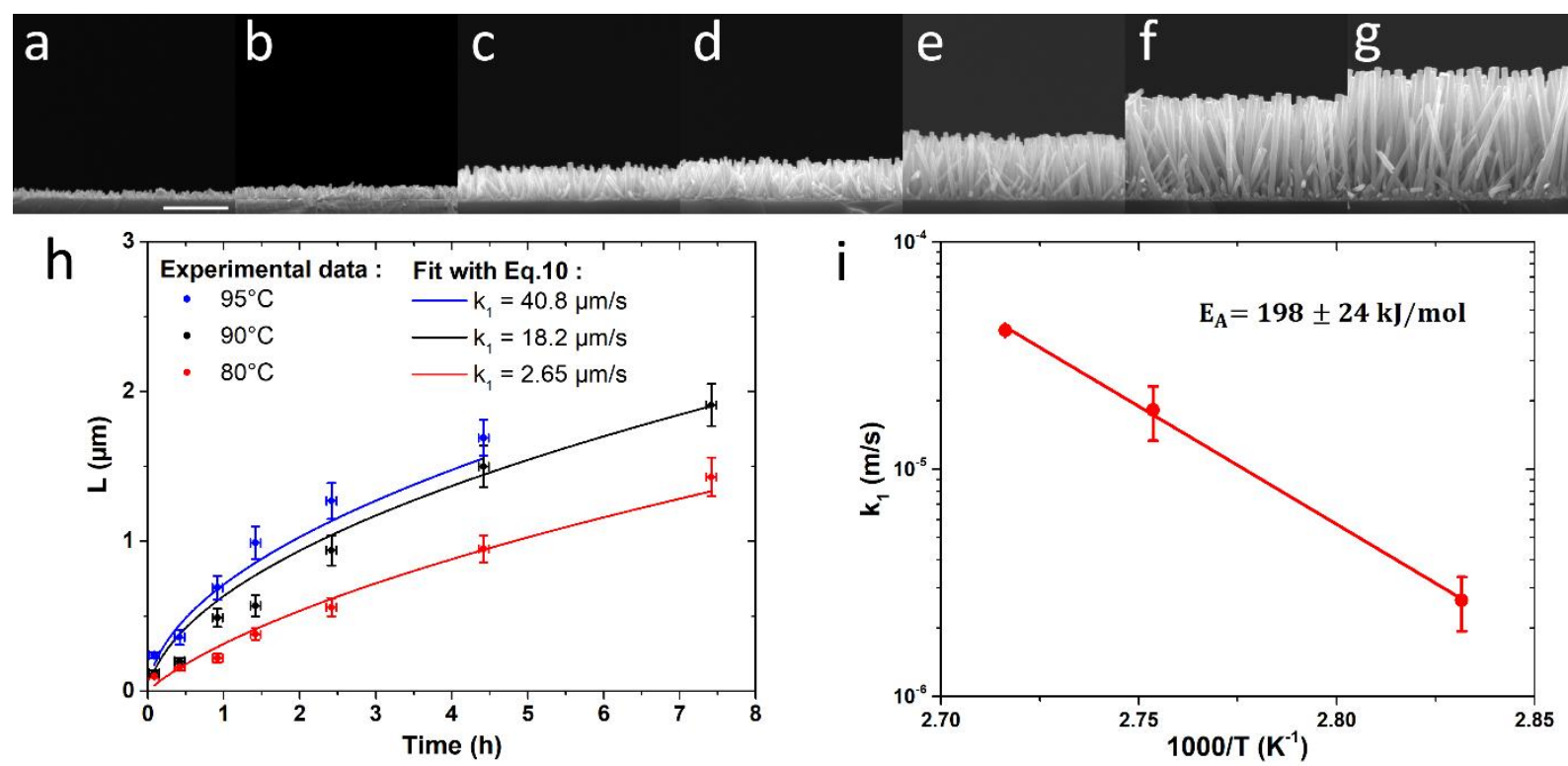

Figure 5. (a-g) Cross-sectional view FESEM images of $\mathrm{ZnO}$ NWs grown by $\mathrm{CBD}$ at $90{ }^{\circ} \mathrm{C}$ with $30 \mathrm{mM}$ of $\mathrm{Zn}\left(\mathrm{NO}_{3}\right)_{2}$ and HMTA for (a) $40 \mathrm{~min}$, (b) $1 \mathrm{~h}$, (c) $1.5 \mathrm{~h}$, (d) $2 \mathrm{~h}$, (e) $3 \mathrm{~h}$, (f) $5 \mathrm{~h}$, and (g) $8 \mathrm{~h}$, respectively. The scale bar represents $1 \mu \mathrm{m}$. (h) Length versus effective growth time of ZnO NWs for each of these series of samples. The experimental data were fitted by Eq.10 with $\Delta C=3.93 \mathrm{mM}, S=0.27, \rho=4.20 \times 10^{28} \mathrm{~m}^{-3}$, and with $k_{1}=$ $2.65 \mu \mathrm{m} / \mathrm{s}$ and $D=2.38 \times 10^{-9} \mathrm{~m}^{2} / \mathrm{s}$ at $80{ }^{\circ} \mathrm{C}, k_{1}=18.2 \mu \mathrm{m} / \mathrm{s}$ and $D=2.74 \times 10^{-9} \mathrm{~m}^{2} / \mathrm{s}$ at $90{ }^{\circ} \mathrm{C}$, and $k_{1}=40.8$ $\mu \mathrm{m} / \mathrm{s}$ and $D=2.93 \times 10^{-9} \mathrm{~m}^{2} / \mathrm{s}$ at $95{ }^{\circ} \mathrm{C}$, using the theoretical model under dynamic conditions. (i) Arrhenius plot of the surface reaction rate constant $k_{1}$ of $\mathrm{ZnO}$ NWs. 


\subsection{Effects of the CBD conditions by using the theoretical model as a predictive}

approach. As the temperature dependence of $k_{1}$ has precisely been established, a predictive approach can be developed to model the elongation process of $\mathrm{ZnO} \mathrm{NWs}$ in a standard sealed reactor for a broad range of CBD conditions. The concentration profile of $\mathrm{Zn}$ (II) species versus effective growth time $t$ and height $z$ above the $\mathrm{ZnO}$ NWs, as deduced from Eq.7, is shown in Figure 6a for the particular case where the growth temperature is $90{ }^{\circ} \mathrm{C}$, $C_{0}=30 \mathrm{mM}$, and $S=0.27$. The effects of the homogeneous growth at $t=0$ where the concentration of $\mathrm{Zn}$ (II) species instantaneously drops of more than $10 \mathrm{mM}$ everywhere in the chemical bath is clearly seen along with the effect of the equilibrium concentration of $\mathrm{Zn}(\mathrm{II})$ species $C_{e q}$ limiting the effective concentration $\Delta C$ to only 3.93 $\mathrm{mM}$ for the elongation process of $\mathrm{ZnO}$ NWs. It is worth noticing that the influence of the homogeneous growth on the value of $\Delta C$ was assessed here through the experimental fit in Figure 5 for a given set of CBD conditions, as it cannot predictively be determined by the present model. However, in a first approximation, $\Delta C$ can be inferred in the most widely used case, where the concentration of $\mathrm{Zn}\left(\mathrm{NO}_{3}\right)_{2}$ and HMTA is equimolar and where no $\mathrm{NH}_{3}$ is added. In these CBD typical conditions, $C_{0} / C_{e q} \sim 2$ as previously discussed in Figure 2 and hence the supersaturation ratio is unchanged. Accordingly, we may roughly assume in these conditions that $\Delta C \sim 0.13 C_{0}$ by taking the homogeneous growth into account. Moreover, it should be noted that the concentration profile of $\mathrm{Zn}$ (II) species does not reach a steady state as it continuously decreases by increasing the growth time, regardless of the height $z$ above the ZnO NWs. Figure $6 \mathbf{b}, \mathbf{c}$ reveals the evolution of the length of $\mathrm{ZnO}$ NWs as a function of effective growth time and temperature, as deduced from Eq.10 in the particular cases where $C_{0}=30 \mathrm{mM}$ and $S=0.27$. For each growth temperature, $k_{1}$ values were deduced from the linear fit in Figure $5 \mathbf{i}$ and $D$ values were inferred from Ref. ${ }^{35}$. For the sake of clarity, the theoretical data are represented both on 3D (Figure 6b) and 2D graphs (Figure 6c) at a given temperature in the range of 60 to $95{ }^{\circ} \mathrm{C}$. Below the growth temperature of $60{ }^{\circ} \mathrm{C}$, the NW growth is negligible, while their length rapidly increases for higher temperatures, which is consistent with what is typically observed experimentally in the literature. ${ }^{48}$ Importantly, we further note that the increase in the length of ZnO NWs with the growth temperature has an inflexion point around $75^{\circ} \mathrm{C}$. This directly indicates that, for related higher values of $k_{1}$, the axial growth rate of $\mathrm{ZnO}$ NWs is predominantly limited by the diffusive transport of $\mathrm{Zn}$ (II) ions. The present predictive approach represents a powerful tool for the optimization of the CBD conditions and the design of a sealed reactor for both fundamental and applied research. 

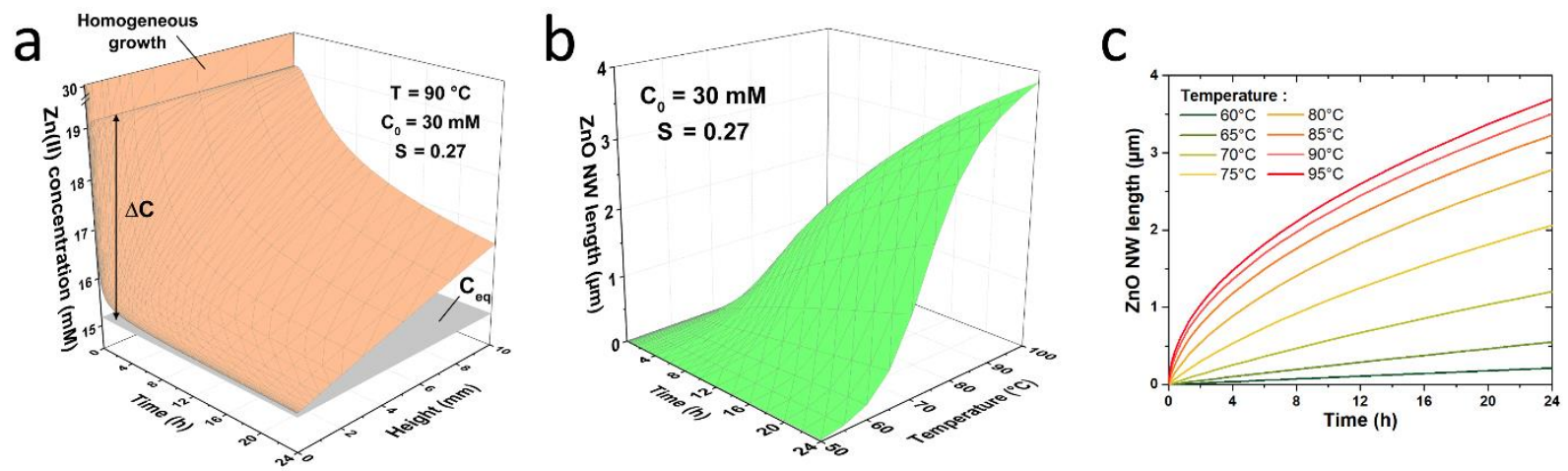

Figure 6. (a) Concentration of $\mathrm{Zn}$ (II) species versus effective growth time $t$ and height $z$ above the ZnO NWs, for a chemical bath at $90{ }^{\circ} \mathrm{C}$ initially containing $30 \mathrm{mM}$ of $\mathrm{Zn}\left(\mathrm{NO}_{3}\right)_{2}$ and HMTA. Eq.7 was used for the plot with $\Delta C$ $=3.93 \mathrm{mM}, C_{e q}=15.18 \mathrm{mM}, k_{1}=18.2 \mu \mathrm{m} / \mathrm{s}, S=0.27, D=2.74 \times 10^{-9} \mathrm{~m}^{2} / \mathrm{s}$, and $\rho=4.20 \times 10^{28} \mathrm{~m}^{-3}$. (b-c) Length of $\mathrm{ZnO}$ NWs versus effective growth time $t$ and temperature $T$, for a chemical bath initially containing 30 $\mathrm{mM}$ of $\mathrm{Zn}\left(\mathrm{NO}_{3}\right)_{2}$ and HMTA. Eq. 10 was used for the plot with $\Delta C=3.93 \mathrm{mM}, S=0.27$ and $\rho=4.20 \times 10^{28} \mathrm{~m}^{-3}$.

For each growth temperature, $k_{1}$ values were deduced from Figure $5 \mathbf{i}$ and $D$ values were inferred from Ref. ${ }^{35}$.

\section{CONCLUSIONS}

In summary, we have established a theoretical model to describe the elongation process of NWs grown by CBD under dynamic conditions, namely in a sealed reactor where the depletion of chemical reactants occurs. The present experimental configuration is used in the vast majority of investigations reported in the literature and dedicated to the synthesis of $\mathrm{ZnO}$ NWs for both fundamental and applied research. Our theoretical model is based on the resolution of Fick's diffusion equations using appropriate boundary conditions in combination with thermodynamic computations yielding the equilibrium concentration of $\mathrm{Zn}$ (II) species. The expression of the axial growth rate of $\mathrm{ZnO}$ NWs and its temporal dependence is determined, namely the evolution of their length vs growth time. That expression is found to be in very good agreement with a large set of experimental data collected at different $\mathrm{pHs}$ and growth temperatures. In particular, we have shown, from the temperature dependence of the surface reaction rate constant $k_{l}$, that the activation energy required for the elongation process of $\mathrm{ZnO} \mathrm{NWs}$ is equal to $198 \pm 24 \mathrm{~kJ} / \mathrm{mol}$. The present value typically involves the energy barriers required i) for the dehydration process of $\mathrm{Zn}(\mathrm{II})$ species (i.e. $\left[\mathrm{Zn}\left(\mathrm{H}_{2} \mathrm{O}\right)_{6}\right]^{2+}$ ions), and ii) for their subsequent direct incorporation onto the $c$-plane faces of ZnO NWs. By using the theoretical model as a predictive approach, a complete growth diagram reporting the evolution of the length of $\mathrm{ZnO}$ NWs vs effective growth time and temperature is gained as a typical illustration. Our theoretical model represents a powerful tool for the careful investigation of the physicochemical processes at work during the $\mathrm{CBD}$ of $\mathrm{ZnO} \mathrm{NWs}$ for fundamental research, but also for the design of a sealed reactor or the 
predictive behavior in a broad range of CBD conditions for applied research and industrial purposes. Eventually, this general approach is of high potential for other systems involving a wide variety of chemicals in solution and of semiconducting materials grown by CBD.

\section{SUPPORTING INFORMATION}

Detailed proof of the dynamic growth model, pictures of the chemical bath, top-view FESEM images of the series at $90{ }^{\circ} \mathrm{C}$ with $800 \mathrm{mM}$ of $\mathrm{NH}_{3}$, cross-sectonial view FESEM images of the series at 80 and $95{ }^{\circ} \mathrm{C}$, NW length and $S$ numerical values of the series at 80,90 and $95^{\circ} \mathrm{C}(\mathrm{PDF})$.

\section{AUTHOR INFORMATION}

\section{Corresponding authors}

*E-mail: bassem.salem@cea.fr

*E-mail: vincent.consonni@grenoble-inp.fr

\section{ORCID}

Clément Lausecker: 0000-0001-8139-4029

Bassem Salem: 0000-0001-8038-3205

Xavier Baillin: 0000-0001-6750-5300

Vincent Consonni: 0000-0003-0171-8746

\section{Notes}

The authors declare no competing financial interests

\section{ACKNOWLEDGEMENTS}

This work was partially supported by the LabEx Minos under the contract ANR-10-LABX-55-01. C. L. held a doctoral fellowship from the LabEx Minos. This research has further benefited from some of the characterization equipments of the Grenoble INP - CMTC platform. V. C. also acknowledges the financial support from the French Research National Agency through the projects ROLLER (ANR-17-CE09-0033) and DOSETTE (ANR-17-CE240003). This work was also partially supported by the French National Research Agency in the framework of the “Investissement d'avenir" program (ANR-15-IDEX-02) through the project CDP NEED. 


\section{REFERENCES}

(1) Sounart, T. L.; Liu, J.; Voigt, J. A.; Hsu, J. W. P.; Spoerke, E. D.; Tian, Z.; Jiang, Y. B. Sequential Nucleation and Growth of Complex Nanostructured Films. Adv. Funct. Mater. 2006, 16, 335-344.

(2) Pawar, S. M.; Pawar, B. S.; Kim, J. H.; Joo, O.-S.; Lokhande, C. D. Recent Status of Chemical Bath Deposited Metal Chalcogenide and Metal Oxide Thin Films. Curr. Appl. Phys. 2011, 11, 117-161.

(3) Willander, M.; Nur, O.; Zhao, Q. X.; Yang, L. L.; Lorenz, M.; Cao, B. Q.; Zúñiga Pérez, J.; Czekalla, C.; Zimmermann, G.; Grundmann, M.; et al. Zinc Oxide Nanorod Based Photonic Devices: Recent Progress in Growth, Light Emitting Diodes and Lasers. Nanotechnology 2009, 20, 332001.

(4) Tian, W.; Lu, H.; Li, L. Nanoscale Ultraviolet Photodetectors Based on Onedimensional Metal Oxide Nanostructures. Nano Res. 2015, 8, 382-405.

(5) Consonni, V.; Briscoe, J.; Kärber, E.; Li, X.; Cossuet, T. ZnO Nanowires for Solar Cells: A Comprehensive Review. Nanotechnology 2019, 30, 362001.

(6) Briscoe, J.; Dunn, S. Piezoelectric Nanogenerators - a Review of Nanostructured Piezoelectric Energy Harvesters. Nano Energy 2015, 14, 15-29.

(7) Wang, Z. L.; Wu, W.; Falconi, C. Piezotronics and Piezo-Phototronics with Third-Generation Semiconductors. MRS Bull. 2018, 43, 922-927.

(8) Theerthagiri, J.; Salla, S.; Senthil, R. A.; Nithyadharseni, P.; Madankumar, A.; Arunachalam, P.; Maiyalagan, T.; Kim, H.-S. A Review on ZnO Nanostructured Materials: Energy, Environmental and Biological Applications. Nanotechnology 2019, 30, 392001.

(9) Greene, L. E.; Law, M.; Goldberger, J.; Kim, F.; Johnson, J. C.; Zhang, Y.; Saykally, R. J.; Yang, P. LowTemperature Wafer-Scale Production of ZnO Nanowire Arrays. Angew. Chem. Int. Ed. 2003, 42, 30313034.

(10) Vayssieres, L.; Keis, K.; Lindquist, S.-E.; Hagfeldt, A. Purpose-Built Anisotropic Metal Oxide Material: 3D Highly Oriented Microrod Array of ZnO. J. Phys. Chem. B 2001, 105, 3350-3352.

(11) Tian, Z. R.; Mckenzie, B.; Konishi, H.; Xu, H.; Voigt, J. A.; Liu, J.; Rodriguez, M. A.; Mcdermott, M. J. Complex and Oriented ZnO Nanostructures. Nat. Mater. 2003, 2, 821-826.

(12) Hsu, J. W. P.; Tian, Z. R.; Simmons, N. C.; Matzke, C. M.; Voigt, J. A.; Liu, J. Directed Spatial Organization of Zinc Oxide Nanorods. Nano Lett. 2005, 5, 83-86. 
(13) Xu, S.; Wang, Z. L. One-Dimensional ZnO Nanostructures: Solution Growth and Functional Properties. Nano Res. 2011, 4, 1013-1098.

(14) Lincot, D. Solution Growth of Functional Zinc Oxide Films and Nanostructures. MRS Bull. 2010, 35, 778789

(15) Richardson, J. J.; Lange, F. F. Controlling Low Temperature Aqueous Synthesis of ZnO. 1. Thermodynamic Analysis. Cryst. Growth Des. 2009, 9, 2570-2575.

(16) McPeak, K. M.; Le, T. P.; Britton, N. G.; Nickolov, Z. S.; Elabd, Y. A.; Baxter, J. B. Chemical Bath Deposition of ZnO Nanowires at Near-Neutral PH Conditions without Hexamethylenetetramine (HMTA): Understanding the Role of HMTA in ZnO Nanowire Growth. Langmuir 2011, 27, 3672-3677.

(17) Strano, V.; Urso, R. G.; Scuderi, M.; Iwu, K. O.; Simone, F.; Ciliberto, E.; Spinella, C.; Mirabella, S. Double Role of HMTA in ZnO Nanorods Grown by Chemical Bath Deposition. J. Phys. Chem. C 2014, $118,28189-28195$.

(18) Parize, R.; Garnier, J.; Chaix-Pluchery, O.; Verrier, C.; Appert, E.; Consonni, V. Effects of Hexamethylenetetramine on the Nucleation and Radial Growth of $\mathrm{ZnO}$ Nanowires by Chemical Bath Deposition. J. Phys. Chem. C 2016, 120, 5242-5250.

(19) Yamabi, S.; Imai, H. Growth Conditions for Wurtzite Zinc Oxide Films in Aqueous Solutions. J. Mater. Chem. 2002, 12, 3773-3778.

(20) Greene, L. E.; Law, M.; Tan, D. H.; Montano, M.; Goldberger, J.; Somorjai, G.; Yang, P. General Route to Vertical ZnO Nanowire Arrays Using Textured ZnO Seeds. Nano Lett. 2005, 5, 1231-1236.

(21) Guillemin, S.; Consonni, V.; Appert, E.; Puyoo, E.; Rapenne, L.; Roussel, H. Critical Nucleation Effects on the Structural Relationship Between ZnO Seed Layer and Nanowires. J. Phys. Chem. C 2012, 116, 2510625111.

(22) Erdélyi, R.; Nagata, T.; Rogers, D. J.; Teherani, F. H.; Horváth, Z. E.; Lábadi, Z.; Baji, Z.; Wakayama, Y.; Volk, J. Investigations into the Impact of the Template Layer on ZnO Nanowire Arrays Made Using Low Temperature Wet Chemical Growth. Cryst. Growth Des. 2011, 11, 2515-2519.

(23) Consonni, V.; Sarigiannidou, E.; Appert, E.; Bocheux, A.; Guillemin, S.; Donatini, F.; Robin, I.-C.; Kioseoglou, J.; Robaut, F. Selective Area Growth of Well-Ordered ZnO Nanowire Arrays with Controllable Polarity. ACS Nano 2014, 8, 4761-4770. 
(24) Xu, S.; Lao, C.; Weintraub, B.; Wang, Z. L. Density-Controlled Growth of Aligned ZnO Nanowire Arrays by Seedless Chemical Approach on Smooth Surfaces. J. Mater. Res. 2008, 23, 2072-2077.

(25) Boubenia, S.; Dahiya, A. S.; Poulin-Vittrant, G.; Morini, F.; Nadaud, K.; Alquier, D. A Facile Hydrothermal Approach for the Density Tunable Growth of ZnO Nanowires and Their Electrical Characterizations. Sci. Rep. 2017, 7, 15187.

(26) Lausecker, C.; Salem, B.; Baillin, X.; Roussel, H.; Sarigiannidou, E.; Bassani, F.; Appert, E.; Labau, S.; Consonni, V. Formation Mechanisms of ZnO Nanowires on Polycrystalline Au Seed Layers for Piezoelectric Applications. Nanotechnology 2019, 30, 345601.

(27) Boercker, J. E.; Schmidt, J. B.; Aydil, E. S. Transport Limited Growth of Zinc Oxide Nanowires. Cryst. Growth Des. 2009, 9, 2783-2789.

(28) Cheng, J. J.; Nicaise, S. M.; Berggren, K. K.; Gradečak, S. Dimensional Tailoring of Hydrothermally Grown Zinc Oxide Nanowire Arrays. Nano Lett. 2016, 16, 753-759.

(29) Cossuet, T.; Appert, E.; Thomassin, J.-L.; Consonni, V. Polarity-Dependent Growth Rates of Selective Area Grown ZnO Nanorods by Chemical Bath Deposition. Langmuir 2017, 33, 6269-6279.

(30) Fick, A. Ueber Diffusion. Ann. Phys. Chem. 1855, 170, 59-86.

(31) Xu, C.; Shin, P.; Cao, L.; Gao, D. Preferential Growth of Long ZnO Nanowire Array and Its Application in Dye-Sensitized Solar Cells. J. Phys. Chem. C 2010, 114, 125-129.

(32) Chen, L.; Li, X.; Qu, L.; Gao, C.; Wang, Y.; Teng, F.; Zhang, Z.; Pan, X.; Xie, E. Facile and Fast One-Pot Synthesis of Ultra-Long Porous ZnO Nanowire Arrays for Efficient Dye-Sensitized Solar Cells. J. Alloys Compd. 2014, 586, 766-772.

(33) Syrrokostas, G.; Govatsi, K.; Yannopoulos, S. N. High-Quality, Reproducible ZnO Nanowire Arrays Obtained by a Multiparameter Optimization of Chemical Bath Deposition Growth. Cryst. Growth Des. 2016, 16, 2140-2150.

(34) Verrier, C.; Appert, E.; Chaix-Pluchery, O.; Rapenne, L.; Rafhay, Q.; Kaminski-Cachopo, A.; Consonni, V. Effects of the $\mathrm{pH}$ on the Formation and Doping Mechanisms of ZnO Nanowires Using Aluminum Nitrate and Ammonia. Inorg. Chem. 2017, 56, 13111-13122. 
(35) Oelkers, E. H.; Helgeson, H. C. Calculation of the Thermodynamic and Transport Properties of Aqueous Species at High Pressures and Temperatures: Aqueous Tracer Diffusion Coefficients of Ions to $1000^{\circ} \mathrm{C}$ and 5 Kb. Geochim. Cosmochim. Acta 1988, 52, 63-85.

(36) Arrhenius, S. Über die Reaktionsgeschwindigkeit bei der Inversion von Rohrzucker durch Säuren. Z. Für Phys. Chem. 1889, 4, 226-248.

(37) Markov, I. V. Crystal Growth for Beginners: Fundamentals of Nucleation, Crystal Growth and Epitaxy, 3rd edition.; World Scientific: New Jersey, 2016; pp 182-189.

(38) Dagnall, S. P.; Hague, D. N.; Towl, A. D. C. X-Ray Diffraction Study of Aqueous Zinc(II) Nitrate. J. Chem. Soc. Faraday Trans. 2 1982, 78, 2161-2167.

(39) Kuzmin, A.; Obst, S.; Purans, J. X-Ray Absorption Spectroscopy and Molecular Dynamics Studies of Hydration in Aqueous Solutions. J. Phys. Condens. Matter 1997, 9, 10065-10078.

(40) Fatmi, M. Q.; Hofer, T. S.; Randolf, B. R.; Rode, B. M. An Extended Ab Initio QM/MM MD Approach to Structure and Dynamics of Zn(II) in Aqueous Solution. J. Chem. Phys. 2005, 123, 054514.

(41) Persson, I. Hydrated Metal Ions in Aqueous Solution: How Regular Are Their Structures? Pure Appl. Chem. 2010, 82, 1901-1917.

(42) McPeak, K. M.; Becker, M. A.; Britton, N. G.; Majidi, H.; Bunker, B. A.; Baxter, J. B. In Situ X-Ray Absorption Near-Edge Structure Spectroscopy of ZnO Nanowire Growth During Chemical Bath Deposition. Chem. Mater. 2010, 22, 6162-6170.

(43) Bock, C. W.; Katz, A. K.; Glusker, J. P. Hydration of Zinc Ions: A Comparison with Magnesium and Beryllium Ions. J. Am. Chem. Soc. 1995, 117, 3754-3765.

(44) Lee, S.; Kim, J.; Park, J. K.; Kim, K. S. Ab Initio Study of the Structures, Energetics, and Spectra of Aquazinc(II). J. Phys. Chem. 1996, 100, 14329-14338.

(45) Hartmann, M.; Clark, T.; van Eldik, R. Hydration and Water Exchange of Zinc(II) Ions. Application of Density Functional Theory. J. Am. Chem. Soc. 1997, 119, 7843-7850.

(46) Rudolph, W. W.; Pye, C. C. Zinc(II) Hydration in Aqueous Solution. A Raman Spectroscopic Investigation and an Ab-Initio Molecular Orbital Study. Phys. Chem. Chem. Phys. 1999, 1, 4583-4593. 
(47) Cossuet, T.; Donatini, F.; Lord, A. M.; Appert, E.; Pernot, J.; Consonni, V. Polarity-Dependent High Electrical Conductivity of $\mathrm{ZnO}$ Nanorods and Its Relation to Hydrogen. J. Phys. Chem. C 2018, 122, $22767-22775$.

(48) Guo, M.; Diao, P.; Cai, S. Hydrothermal Growth of Well-Aligned ZnO Nanorod Arrays: Dependence of Morphology and Alignment Ordering upon Preparing Conditions. J. Solid State Chem. 2005, 178, 18641873.

(49) Goux, A.; Pauporté, T.; Chivot, J.; Lincot, D. Temperature Effects on ZnO Electrodeposition. Electrochimica Acta 2005, 50, 2239-2248.

\section{TOC Graphic}

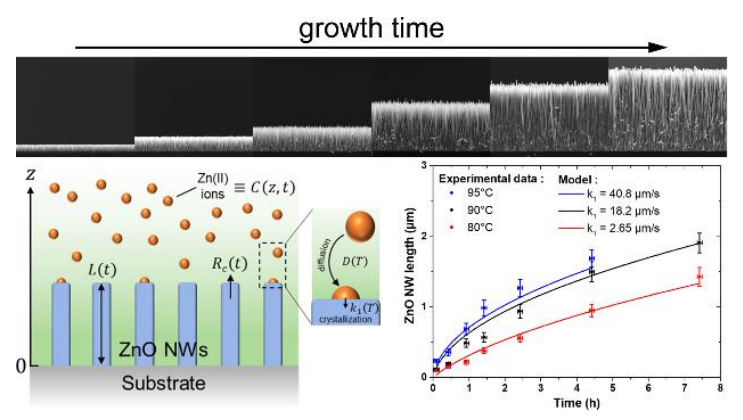

